\title{
An Assessment of RELAP5 MOD3.1.1 Condensation Heat Transfer Modeling with GIRAFFE Heat Transfer Tests •
}

\author{
Brian D. Boyer, Yüksel Parlatan, Gregory C. Slovik, and Upendra S. Rohatgi, Brookhaven National \\ Laboratory
}

ABSTRACT

RELAP5 MOD3.1.1 is being used to simulate Loss of Coolant Accidents (LOCA) for the Simplified Boiling Water Reactor (SBWR) being proposed by General Electric (GE). One of the major components associated with the SBWR is the Passive Containment Cooling System (PCCS) which provides the long-term heat sink to reject decay heat [1]. The RELAP5 MOD3.1.1 code [2] is being assessed for its ability to represent accurately the PCCS. Data from the Phase 1, Step 1 Heat Transfer Tests performed at Toshiba's Gravity-Driven Integral Eull-Height Test for Passive Heat Removal (GIRAFFE) facility [3] will be used for assessing the ability of RELAP5 to model condensation in the presence of noncondensables.

The RELAP5 MOD3.1.1 condensation model uses the University of California at Berkeley (UCB) correlation developed by Vierow and Schrock [4]. The RELAP5 code uses this heat transfer coefficient with the gas velocity effect multiplier being limited to $2[5,6]$. This heat transfer option was used to analyze the condensation heat transfer in the GIRAFFE PCCS heat exchanger tubes in the Phase 1. Step 1 Heat Transfer Tests which were at a pressure of 3 bar and had a range of nitrogen partial pressure fractions from 0.0 to 0.10 .

The results of a set of RELAP5 calculations at these conditions were compared with the GIRAFFE data. The effects of PCCS cell nodings on the heat transfer process were also studied. The UCB correlation, as implemented in RELAP5, predicted the heat transfer to $\pm 5 \%$ of the data with a three-node model. The three-node model has a large cell in the entrance region which smeared out the entrance effects on the heat transfer, which tend to overpredict the condensation. Hence, the UCB correlation predicts condensation heat transfer in the presence of noncondensable gases with only a coarse mesh. The cell length term in the condensation heat transfer correlation implemented in the code must be removed to allow for accurate calculations with smaller cell sizes.

\section{INTRODUCTION}

The PCCS is a new and unique safety feature for Advanced Light Water Reactors (ALWR). Figure 1 shows the containment and passive heat removal systems of an ALWR called the SBWR. By condensing the steam vented into the drywell from the Depressurization Valves (DPVs), a steam line break, or any line break in the reactor coolant system, the SBWR can prevent the drywell pressure from increasing to unacceptable levels during a LOCA. Because the drywell is inerted with nitrogen gas to prevent hydrogen explosions and fires, the PCCS will have to condense the steam in the presence of noncondensable gases. As the steam condenses in the tubes of the PCCS, the heat is transferred to a pool of saturated water containing the PCCS unit. The condensate from the PCCS drains

- This work performed under the auspices of the U.S. Nuclear Regulatory Commission.

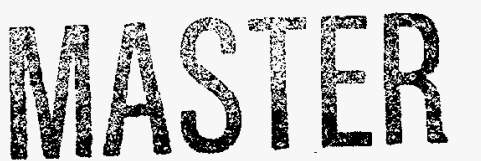
DISTRIBUTION OF THIS DOCUMENT IS UNLIMITEDON? 
to the Gravity-Driven Cooling System (GDCS) tank to be returned to the Reactor Pressure Vessel (RPV). Eventually, the nitrogen gas that accumulates in the PCCS is purged to the Suppression Chamber $(S / C)$ through a vent tube submerged in the Suppression Pool (S/P). Purging occurs when the pressure drop between the drywell and the $S / C$ is sufficient to overcome the static head of the submergence of the vent tube, which is about $7 \mathrm{kPa}$.

It is necessary to remove nitrogen from the PCCS to enable the heat transfer rate to be high enough to remove enough energy from containment to reduce containment pressure. The nitrogen purging process in the PCCS will be an oscillatory process which will affect the heat removal rate in the PCCS. As the steam condenses, the nitrogen gas will tend to build up in the PCCS tubes. This nitrogen will gradually blanket large amounts of the liquid condensate film that has condensed on the tube surface. This increasing nitrogen layer will degrade the condensation process reducing the flow through the PCCS tubes and increasing the pressure difference between the drywell and the S/C.

As the pressure difference between the drywell and the S/C rises high enough to overcome the static head in the bottom of the nitrogen vent tube, the accumulated nitrogen will be purged out of the PCCS and into the S/C. The vapor flow into the PCCS will increase and purge the nitrogen out of the PCCS. Since the PCCS nitrogen concentration was made lower by the purging process, the condensing process can begin again. As condensation resumes, the pressure differential between the drywell and the S/C decreases forcing the venting process to terminate. As the steam condenses, the nitrogen gas will be stripped off the steam and will build up in the PCCS tubes to start the cycle over again.

The test program for the PCCS developed by Toshiba, for GE, is known as the Gravity-Driven Integral Full-Height Test for Passive Heat Removal (GIRAFFE) [1,3]. GIRAFFE demonstrates the ability of the PCCS to operate in the long-term heat rejection period of a SBWR LOCA. In the Phase 1, Step 1 test series various steady-state vapor flow rates, system pressures, and nitrogen concentrations were used in a separate effects test to examine the performance of the PCCS component. These flow rates and nitrogen concentrations are in the expected ranges for the long-term cooling period of an SBWR LOCA. The GIRAFFE Phase 1, Step 1 test results were also used to assess the ability of RELAP5 to predict condensation of steam in the presence of noncondensables and to model the venting of noncondensable gases to the $S / C$. Since the vent line tube was not submerged in the $S / P$ water, the venting and heat transfer were steady-state processes in these tests. The effect of various cell nodings of the PCCS tubes was also investigated.

\section{GIRAFFE FACILITY DESCRIPTION}

GIRAFFE is a full-height test facility scaled $1 / 400$ by volume and power. Toshiba designed GIRAFFE to preserve elevations and local pressure losses to capture data demonstrating the passive heat removal system [1,3]. The radial dimensions are scaled $1 / 20$ while all the relative elevations of the SBWR have been preserved to achieve natural circulation flows typical of the SBWR. The GIRAFFE facility attempts to maintain (1) the gravity-driven circulation paths throughout the containment for liquid and vapor phases; (2) the nitrogen partial pressure in each volume; (3) the nitrogen transfer rate from one volume to another; and the (4) nitrogen accumulation in the PCCS 


\section{DISCLAIMER}

Portions of this document may be illegible in electronic image products. Images are produced from the best available original document. 
condenser tubes. Hence, GIRAFFE's ability to represent the gravity forces, nitrogen gas concentrations, and the small pressure differences in the SBWR is important for the data collected at the GIRAFFE test facility.

The GIRAFFE Phase 1, Step 1 configuration is shown in Figure 2. The test facility included components for the reactor pressure vessel (RPV), the suppression chamber (S/C), and the isolation condenser pool containing the PCCS heat exchanger unit. The PCCS heat exchanger consists of an upper plenum (steam box) to represent the steam injection, three heat exchanger tubes, and a lower plenum (water box) which collects the liquid. The condensate drains out the water box to the RPV and the noncondensable gas vents to the S/C. As stated previously, in the latest version of the SBWR, the condensate will no longer drain directly to the RPV from the PCCS but will drain to the GDCS tank. However, the GIRAFFE Phase 1, Step 1 configuration will not distort the heat transfer and fluid flow phenomena being investigated.

The data from the Phase 1, Step 1 series of tests was used to assess RELAP5. In the Phase 1, Step 1 tests, steam and nitrogen were injected as boundary conditions at various nitrogen partial pressures into the PCCS. The steadystate condensation rates and temperature profiles were examined in this test. This test provided data on the steadystate behavior of the PCCS with prototypical flow, pressure, and nitrogen concentration conditions likety to be seen in a SBWR LOCA.

\section{RELAP5 Heat Transfer Package}

RELAP5 has been used to model the GIRAFFE Phase 1, Step 1 Heat Transfer Tests. The RELAP5 noncondensable heat transfer package is based on the UCB correlation by Vierow and Schrock $[4,5,6]$. The RELAP5 MOD 3.1.1 implementation of the correlation is:

$$
\begin{aligned}
& h_{\exp }=f_{1} f_{2}{ }_{t} \\
& h_{t}=3.185811\left|\frac{\Delta Z_{c} D_{h}}{L_{c}^{2}}\right|_{\text {cond }} \\
& h_{\text {cond }}=0.296\left[\left.\frac{\rho_{f}\left(\rho_{f}-\rho_{g}\right) g h_{f g} k_{f}^{3}}{D_{h} \mu_{f}\left(T_{g i}-T_{w}\right)}\right|^{1 / 4}\right. \\
& f_{1}=\min \left[2,1+2.88\left(10^{-5}\right) R_{g}^{1.118}\right] \\
& f_{2}=1-C^{*} M^{b}
\end{aligned}
$$


with $h_{\text {cond }}$ being a laminar film condensation heat transfer coefficient derived by Chato [ 7 ] for horizontal pipes. $C$ and $b$ are factors that take into account the effect of gas mass fraction in the following fashion:

$$
\begin{array}{llll}
C=10, & b=1.0 & \text { for } & M_{a}<0.063 \\
C=0.938, & b=0.13 & \text { for } & 0.063<M_{a}<0.60 \\
C=1.0, & b=0.22 & \text { for } & M_{a}>0.60
\end{array}
$$

for different gas mass fractions. It should be noted that in the entrance region of a pipe where condensation is occurring the gas Reynolds number will be at its highest value. As the liquid condenses out of the vapor, the vapor velocity drops and the gas Reynolds number decreases. Hence, the dependence on gas Reynolds number can increase the gas velocity effect by a large amount in the entrance region.

Schrock has recommended that a limit of 2 be placed on the gas velocity effect factor, $f_{1}$, to avoid overpredicting the heat transfer in the entrance region. In a study of approaches to modeling condensation phenomena in the PCCS, Tills [8] found that the multiple linear regression technique for analyzing the heat transfer data produced a correlation that appears to predict heat transfer well over the wide range of data points. However, the wayward scattered points may not be random scatter. Points that are far from the calculated curve may be correlated to each other by their position in the tube. Lumping all the data together ignored local phenomena such as the entrance effect on the heat transfer coefficient.

\section{RELAP5 PhASE 1, STEP 1 MODEL}

A RELAP5 MOD3.1.1 model of the GIRAFFE test facility (Figure 2) for the Phase 1, Step 1 Heat Transfer tests is shown in Figures 3 and 4. It has components representing the PCCS, the RPV, and the S/C. In GIRAFFE, the steam and noncondensable gases were injected into the PCCS at constant flow rates. The RELAP5 model simulated this behavior by using a time-dependent volume and a time-dependent junction to specify flow and pressure boundary conditions. In GIRAFFE, the nitrogen purged to the S/C. During normal operation of the PCCS, uncondensed steam and nitrogen being purged to the S/P will cause condensation chugging and flow oscillations. As in the GIRAFFE tests, the S/C was kept empty of liquid to avoid oscillatory flow and heat transfer phenomena. The liquid drained out of the PCCS to the RPV which functioned as a collection tank. The RPV had a small amount of water at the tank bottom as its initial condition. Toshiba ran a line from the RPV to the S/C to equalize pressure between these two vessels. The pressure in the condensate collection tank and the purging tank were identical to avoid having a pressure gradient develop between the RPV and S/C that would cause gas flow to the RPV, liquid flow to the S/C, or even reverse flow from the S/C or the RPV to the PCCS. A valve on the S/C opened to vent out the purged gases at the rate that they were accumulating in the S/C [9]. A RELAP5 VALVE component simulated the vent valve by opening when pressure exceeded the nominal system pressure and by closing when the pressure dropped below the nominal system pressure.

The pool that the PCCS resides in was not explicitly modeled. RELAP5 being a one-dimensional fluid flow code could not simulate the two-dimensional nature of the natural convection pool boiling occurring in the pool. Therefore, a 
table of heat transfer correlations for pool boiling, shown in Table 1, was developed from literature [10-14] to use for GIRAFFE and SBWR modeling.

Models have been developed to predict four Phase 1, Step 1 tests that have a system pressure of 3 bar and a steam flow rate of $0.03 \mathrm{~kg} / \mathrm{s}$. The nitrogen partial pressure fraction was varied in the four cases by keeping the steam flow rate at $0.03 \mathrm{~kg} / \mathrm{s}$ and adding nitrogen to the inlet flow to reach the proper nitrogen concentration (nitrogen partial pressure fractions $=0.0,0.02,0.05$, and 0.10 ). The heat transfer coefficients, overall heat transfer, and gas volume temperatures were calculated. The gas volume temperatures were compared to the temperatures obtained from six thermocouple positions in the GIRAFFE test [3]. The RELAP5 PCCS model used 5 different nodings of evenly spaced cells $(3,6,12,18$, and 24 cells) to explore the effects of cell noding on the heat transfer calculations.

\section{PHASE 1, STEP 1 TEST ASSESSMENT WITH UCB CORRELATION-RELAP5 RESULTS}

Figures 5 through 8 show the RELAP5 predicted heat transfer coefficients for Phase 1, Step 1 and Figures 9 through 12 show the gas temperatures in the tube calculated by RELAP5 and the bulk tube temperatures from GIRAFFE test data for the Phase 1, Step 1 tests with nitrogen partial pressure fractions of $0.0,0.02,0.05$, and 0.10 , respectively. The RELAP5 flow and pressure input derived from GIRAFFE data is assumed to have an accuracy of $\pm 2 \%$ corresponding to the accuracy of the flow and pressure instrumentation in the GIRAFFE facility [9]. The heat transfer coefficients and gas temperatures from the RELAP5 calculations are plotted in Figures 5 through 12 on the $x$-axis at the point corresponding to the mesh cell center. The origin is the top of the $2.4 \mathrm{~m}$ PCCS tubes. The GIRAFFE temperature test data were obtained from a bulk temperature probe located in the center of one of the three PCCS tubes. The $x$-axis locations for the test data are the positions of the thermocouples on the bulk femperature probe.

As shown in Table 2, the pool-side heat transfer coefficients are of the same order of magnitude as the tube-side heat transfer coefficients. The pool-side heat transfer coefficients are larger than the tube-side heat transfer coefficients except in the entrance region of the GIRAFFE test with pure steam. Hence, except in the entrance region of the GIRAFFE test with pure steam, the limiting resistance to beat transfer lies in the PCCS tubes.

The predicted heat transfer coefficients show the effects of the cell length dependence, as expected from the $\Delta Z_{c}{ }^{\prime}$ $\mathrm{L}_{c}{ }^{2}$ term in Equation 2. As the number of nodes increased, the heat transfer coefficient increased. A comparison of Figures 5 through 8 illustrates the effect. With increasing nitrogen concentration the effect is more dramatic. The heat transfer coefficient increases to its greatest value at the tube entrance. Figure 5 shows that the cell length dependence on the gas velocity effect allows a higher maximum heat transfer coefficient with increasing cell numbers. Furthermore, this limit of two still appears to be high, especially for the cases with steam and nitrogen mixed.

As shown by Equation 4, the plateau in the heat transfer coefficients in Figure 5 is created by the high gas velocities near the tube entrance in the tests with pure steam cases. The high gas Reynolds number push the gas velocity effect number, $f_{2}$, to the maximum of two where the plateau occurs. Since the vertical film condensation heat transfer coefficient, $h_{t}$, should be nearly constant and the noncondensable gas degradation factor, $f_{2}$, is equal 
to one in a pure steam environment, when $f_{1}$ is equal to two the condensation heat transfer coefficient will remain a constant. When $\mathrm{Re}_{\mathrm{g}}$ falls below 11,518 , the condensation heat transfer coefficient will drop below the plateau.

The temperatures in Figures 9 through 12 provide a direct comparison of RELAP5 calculations to GIRAFFE data (contains error bars of $\pm 1^{\circ} \mathrm{C}$ ). It can be seen that the three-cell and six-cell nodings predict the temperature profiles within $1-2^{\circ} \mathrm{C}$ of the GIRAFFE data in the two cases with the lowest nitrogen concentrations. The 12-,18-, and 24-cell node cases show up to $10^{\circ} \mathrm{C}$ deviation from the data by the exit of the PCCS in the two cases with the lowest nitrogen concentrations. In the two cases with the highest nitrogen concentrations, the RELAP5 entrance temperatures are $3^{\circ} \mathrm{C}$ greater than the GIRAFFE data and the data shows a temperature rise from the first thermocouple to the second thermocouple. The RELAP5 temperatures are consistent with the saturation temperatures for the partial pressures of steam for the two highest nitrogen concentration cases. Therefore, there may be experimental errors in the GIRAFFE bulk temperatures or pressure drops in the feed lines to the PCCS that are not included in the RELAP5 model. As in the two cases with the lowest nitrogen concentrations, the RELAP5 three-cell noding and the six-cell noding results show agreement within $1-2^{\circ} \mathrm{C}$ of the data. However, the twelve-cell noding also shows agreement of 1 $2^{\circ} \mathrm{C}$ with the data and the runs with 18 and 24 cells are not appreciably different than the data.

As seen in Figure 9, the test with pure steam had a temperature plateau not seen in the tests with nitrogen present (Figures 10 through 12). Since the pressure drop in the PCCS tubes is small, the temperature stays at a constant saturation temperature until full condensation occurs and subcooling occurs. On the other hand, in the tests with nitrogen present, the saturation temperature drops as the partial pressure of steam decreases as the nitrogen content of the vapor mixture increases.

Since the tube exit temperatures decreases in all cases with increasing cell numbers, increasing the number of cells resulted in higher heat transfer. To get an idea of how much the cell noding affected heat transfer, the total heat transfer, as shown in Figure 13, must be examined. When nitrogen is added to the vapor mixture the total heat transfer calculated by RELAP5 is around $10 \%$ too high when compared to the GIRAFFE data for the cases with 6 cells. It is up to 20 to $33 \%$ too high when compared to the GIRAFFE data for the cases with 12,18 , and 24 cells. The three-cell noding calculated heat transfer that was at most $\pm 5 \%$ off the GIRAFFE data.

The increase in heat transfer caused by increasing cell noding is more pronounced with increasing concentrations of noncondensable gases. In the test with pure steam, the condensation length is less than the total tube length. Theretore, as cell nodes increase in pure steam flow, condensation length decreases. However, the cell noding effect on sensible heat removal is nearly negligible and the total heat transfer is affected by only $2 \%$ by increasing cell nodes from 3 to 24. As noncondensable gas is added to steam, the heat transfer is degraded enough to prevent total condensation of the steam within the PCCS tube length and the cell noding effect on heat transfer is felt over the entire length of the tube causing a $20 \%$ to $33 \%$ increase in heat transfer as seen in Figure 13.

Since the UCB correlation overpredicts the heat transfer in the entrance region of a condensing tube [8], numerical homogenizing of the void fractions, air mass tractions, and gas and liquid velocities with decreasing cell nodes can reduce the entrance effect. Hence, the three-cell noding most closely reproduces both the GIRAFFE heat transfer (Figure 13) and temperature profiles. However, the code user must be aware that this effect is a product of the approach taken to implement the UCB heat transfer correlation in RELAP5 MOD3.1.1. 


\section{CONCLUSION}

This study showed that the RELAP5 MOD3.1.1 implementation of the UCB correlation has a tendency to overpredict the heat transfer in the entrance region of the tube. Furthermore, and that increasing the noding in RELAP5 MOD3.1.1 has a profound effect on the heat transfer coefficient. The RELAP5 MOD3.1.1 implementation of the UCB correlation does overpredict heat transfer in the entrance region of a tube but the use of three large cells in the RELAP5 PCCS model will smooth out the effect and produce satisfactory agreement with the data. However, it is recommended that this version of RELAP5 should remove the cell length term in the condensation heat transfer correlation to avoid its effect on the heat transfer caused from using different cell sizes. If this change is implemented, another noding study should be conducted and the recommendation of using three cells reevaluated.

\section{ACKNOWLEDGEMENT}

The authors would like to acknowledge the support of the United States Nuclear Regulatory Commission in funding this research.

\section{REFERENCES}

[1] Shiralkar, B., et al., "SBWR Test and Analysis Program Description," NEDO-32391, Rev. A, General Electric Company (1994).

[2] Carlson, K.E., et al., "RELAP5/MOD3 Code Manual," NUREG/CR-5535 (1990).

[3] Nagasaka, H., et al., "Heat Removal Tests of Isolation Condenser Applied as a Passive Containment System", Proceedings of the 1st JSME/ASME Joint International Conference on Nuclear Engineering (ICONE-1), 265-271 (1991).

[4] Vierow, K.M., and Schrock, V.E., "Condensation in a Natural Circulation Loop with Noncondensable Gas Present, Part I Heat Transier," Japan-US Seminar on Two-Phase Elow Dynamics, Berkeley, CA (1992).

[5] Shumway, R.W., "Condensation Models for SBWR," INEL Draft Report, (1992).

[6] Shumway, R.W., "Wall Condensation Improvements in RELAP5/MOD3.1," INEL Draft Report, (1993).

[7] Chato, J.C., "Laminar Condensation Inside Horizontal and Inclined Tubes," ASHRAE, 4, 52-60 (1969).

[8] Tills, J., "Letter Report on PCCS Modeling for SBWR," Containment Modeling Department, Sandia National Laboratory, Albuquerque, NM (1994).

[9] Arai, K., Personal Communication (1994).

[10] Kakaç, S., et al., editors, Handbook of Single-Phase Convective Heat Transfer, John Wiley \& Son, 12-24 (1987).

[11] Nishikawa, K., et al., "Effect of Heating Surface Orientation on Nucleate Boiling Heat Transfer," Proc. ASMEJSME Thermal Eng, Jeint Conf, (1983).

[12] Carey, V.P., Liquid-Vapor Phase-Change Phenomena; An Introduction to the Thermophysics of Vaporization and Condensation Processes in Heat Transfer Equipment, Hemisphere Publishing Corporation, Washington, 238-243 (1992). 
[13] Bui, T.D. and Dhir, V.K., "Transition Boiling Heat Transfer on a Vertical Surface," J. Heat Transfer, 107, 756-763 (1985).

[14] Bui, T.D. and Dhir, V.K., "Film Boiling Heat Transfer on an Isothermal Vertical Surface," L.Heat Transfer, 107, 764-771 (1985).

\section{TABLE OF NOMENCLATURE}

$D_{h}=$ hydraulic diameter for heat transfer, $m$

$\Delta Z_{c}=$ RELAP5 cell change in elevation, $m$

$f_{1}=$ gas velocity factor

$f_{2}=$ noncondensable gas degradation factor

$g=$ acceleration of gravity, $\mathrm{m} / \mathrm{s}^{2}=9.81 \mathrm{~m} / \mathrm{s}^{2}$

$G_{g}=$ gas mass velocity, $\mathrm{kg} / \mathrm{m}^{2}$-sec

$h_{\text {cond }}=$ laminar film condensation heat transfer coefficient, W/m²-K

$h_{\text {exp }}=U C B$ heat transfer coefficient, W/m²-K

$h_{f g}=\quad$ latent heat of vaporization, $\mathrm{kJ} / \mathrm{kg}$

$h_{t}=$ vertical film condensation heat transfer coefficient, W/m $2-K$

$k_{f}=\quad$ liquid conductivity, $W / m-K$

$L_{c}=$ RELAP5 cell length, $m$

$M_{\mathrm{a}}=$ gas mass fraction

$R e_{g}=G_{g} D_{h} / \mu_{g}=$ gas Reynolds number

$T_{g i}=\quad$ interfacial temperature, $\mathrm{K}$

$T_{w}=\quad$ wall temperature, $K$

$\delta_{1}=\quad$ liquid film thickness, $m$

$\mu_{g}=$ gas viscosity, $\mathrm{N}-\mathrm{sec} / \mathrm{m}^{2}$

$\mu_{1}=\quad$ liquid viscosity, $\mathrm{N}-\mathrm{sec} / \mathrm{m}^{2}$

$\rho_{g}=$ density of gas, $\mathrm{kg} / \mathrm{m}^{3}$

$\rho_{f}=$ density of liquid, $\mathrm{kg} / \mathrm{m}^{3}$. 


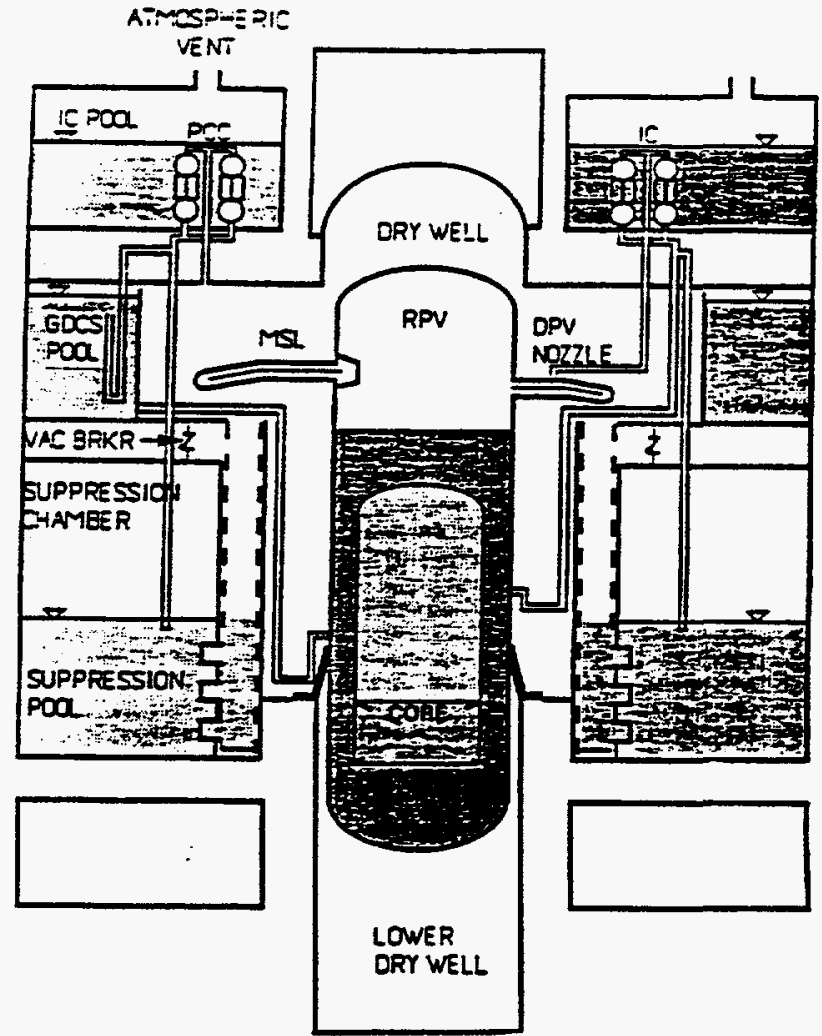

Figure 1: SBWR

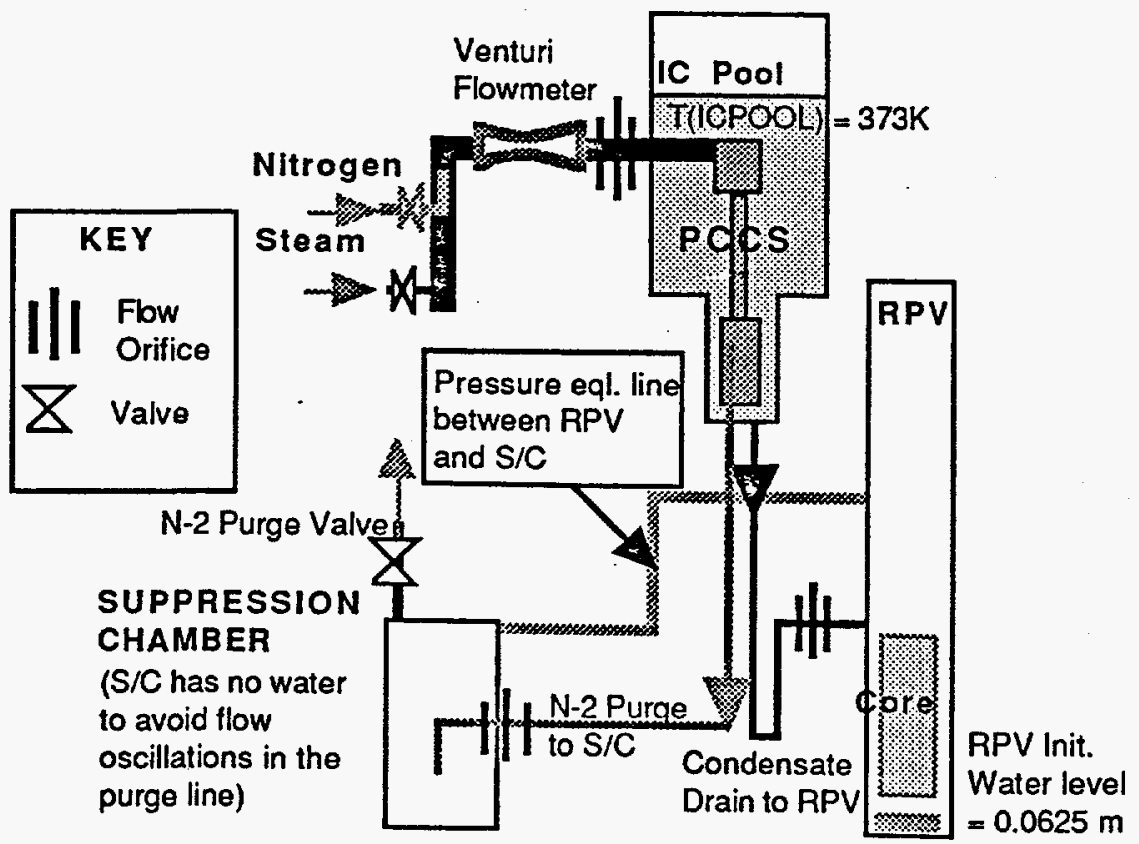

Figure 2: Phase 1, Step 1 Configuration 


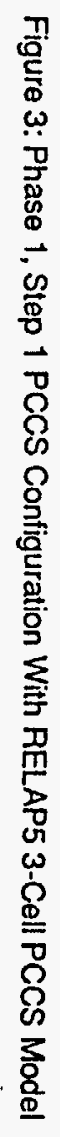
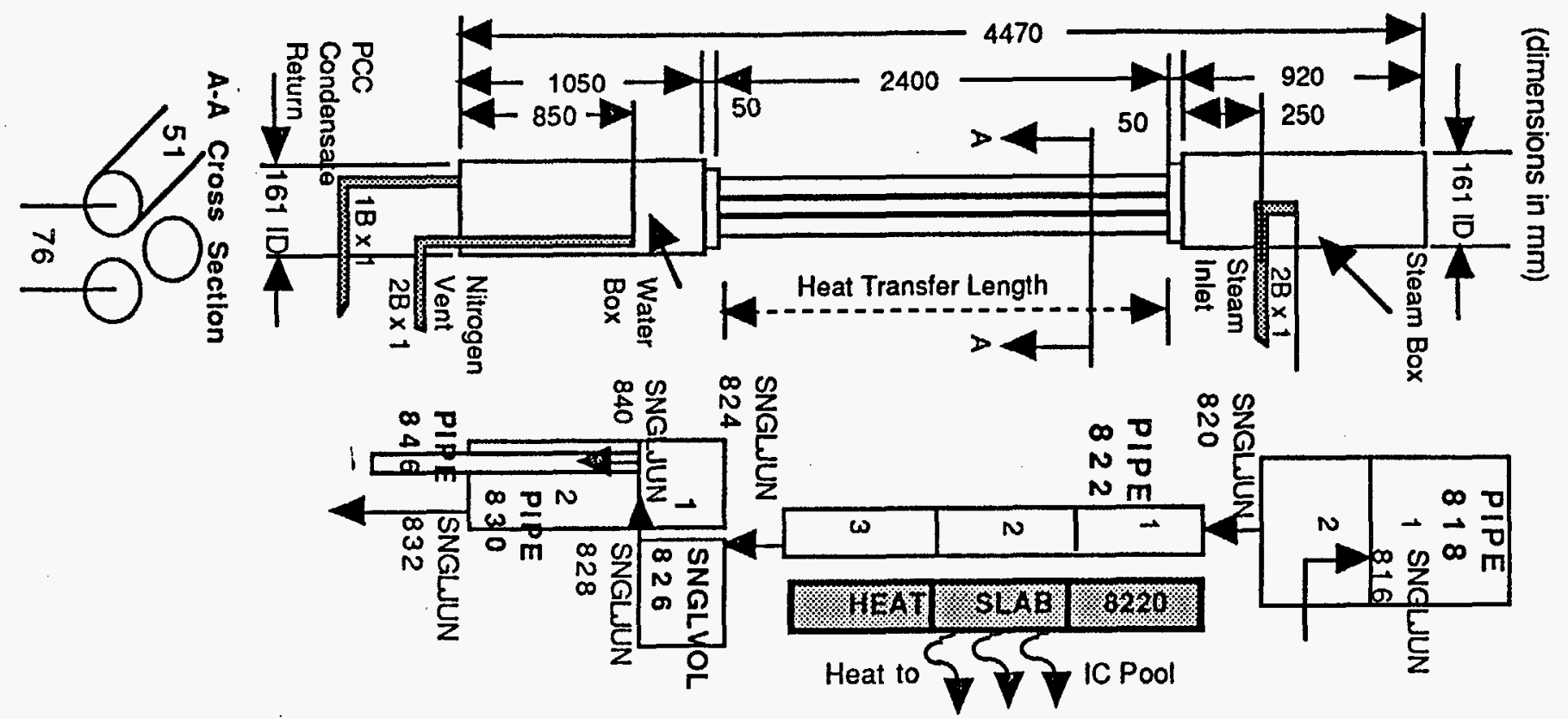


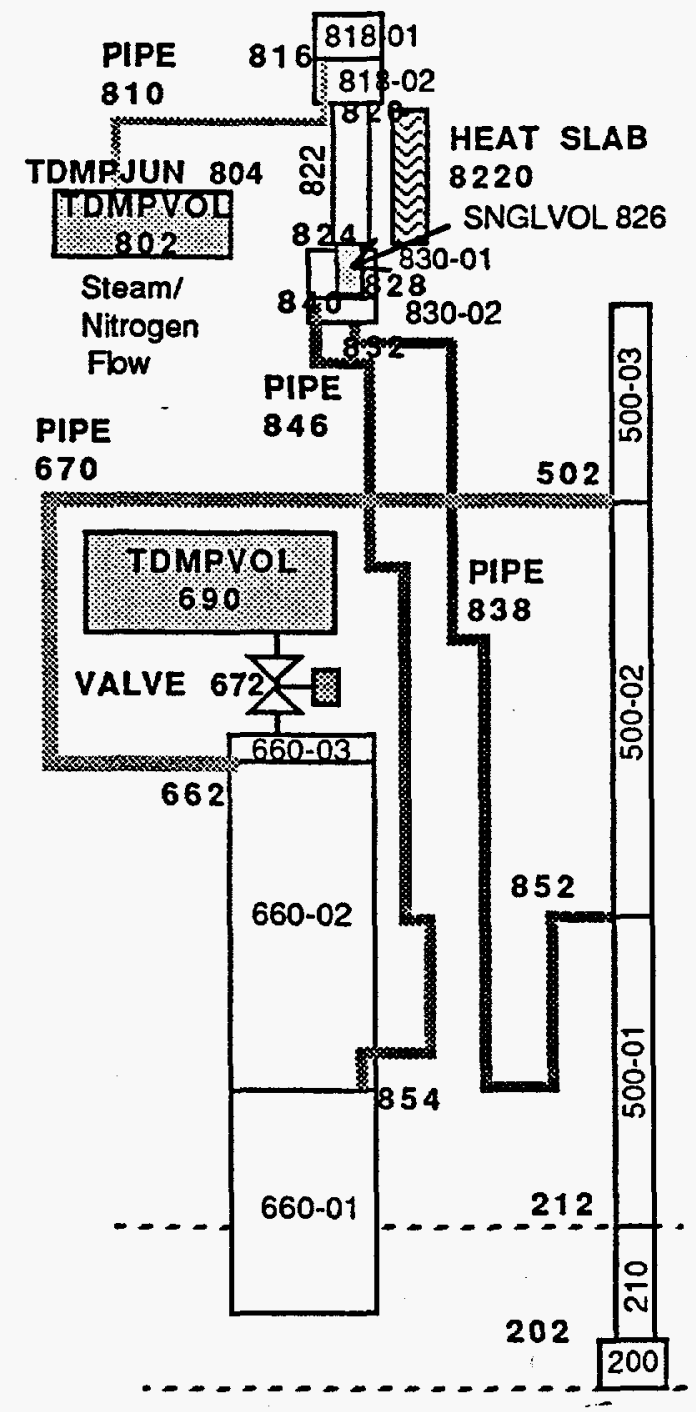

Figure 4: Phase 1, Step 1 BNL RELAP5 Model 


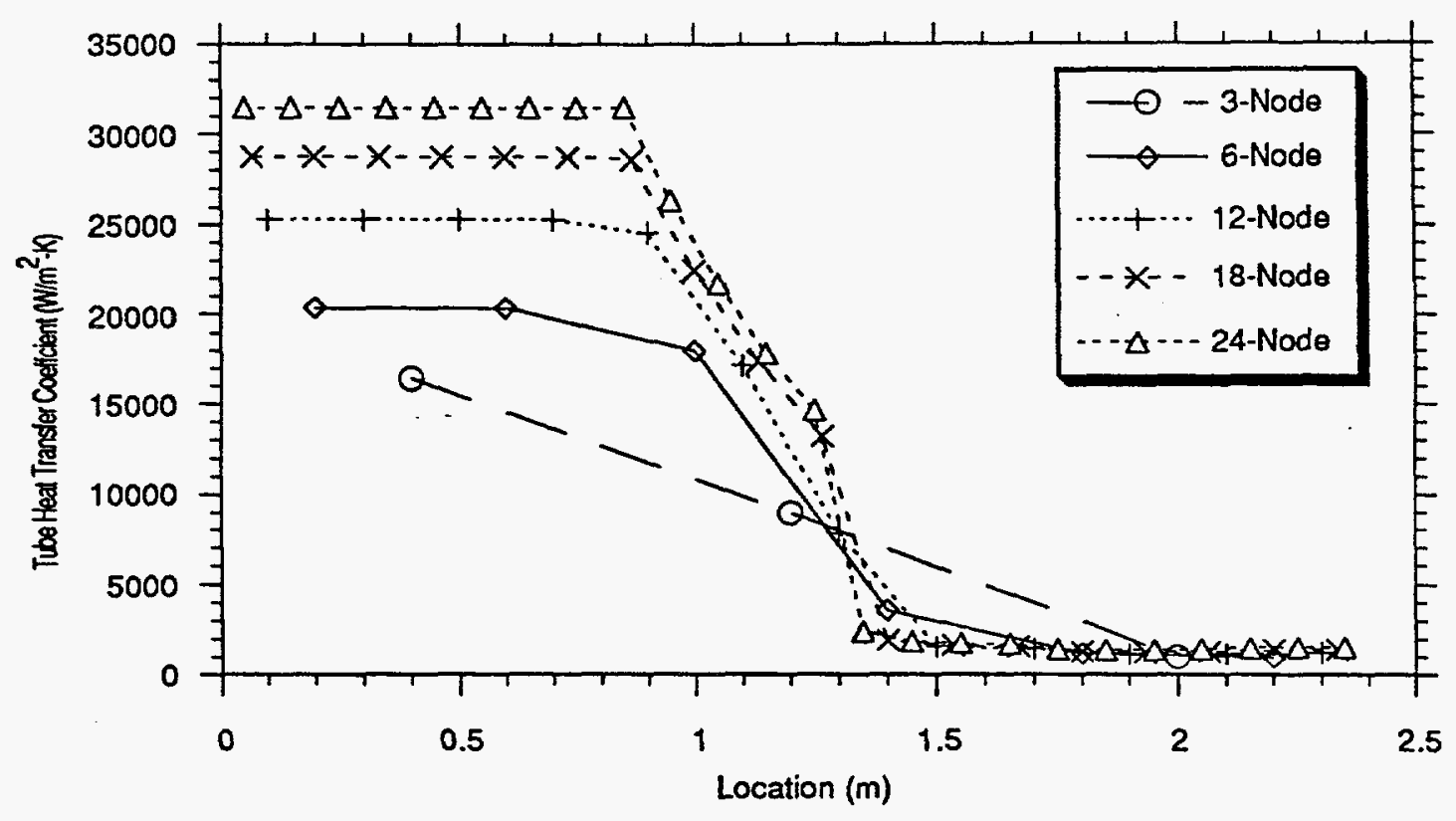

Figure 5: GIRAFFE - Phase 1, Step 1 Test $-P_{\mathrm{N} 2} / P_{\text {total }}=0.0-$ Heat Transfer Coefficients

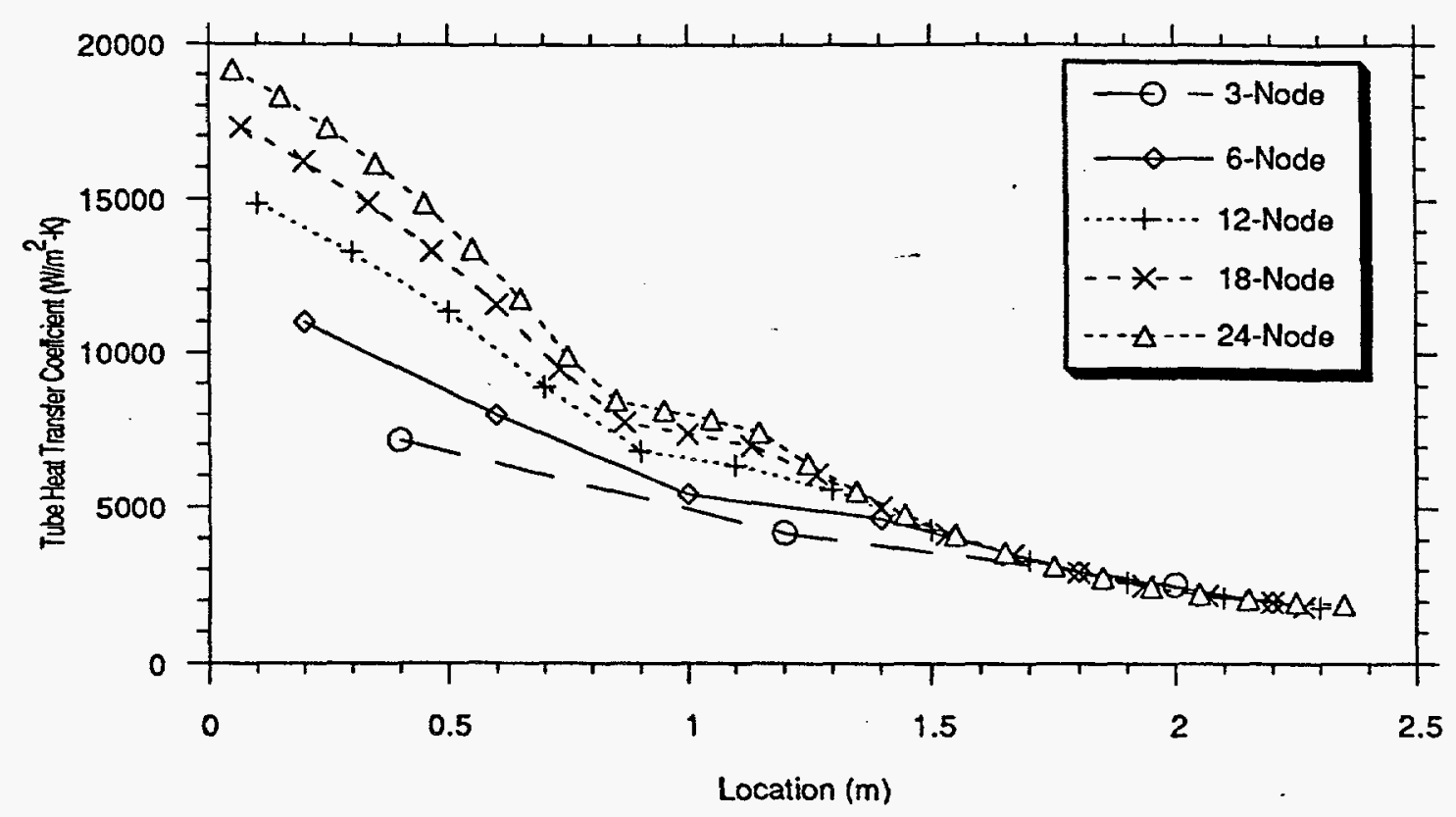

Figure 6: GIRAFFE - Phase 1, Step 1 Test $-P_{N_{2} / P_{\text {total }}}=0.02-$ Heat Transfer Coefficients 


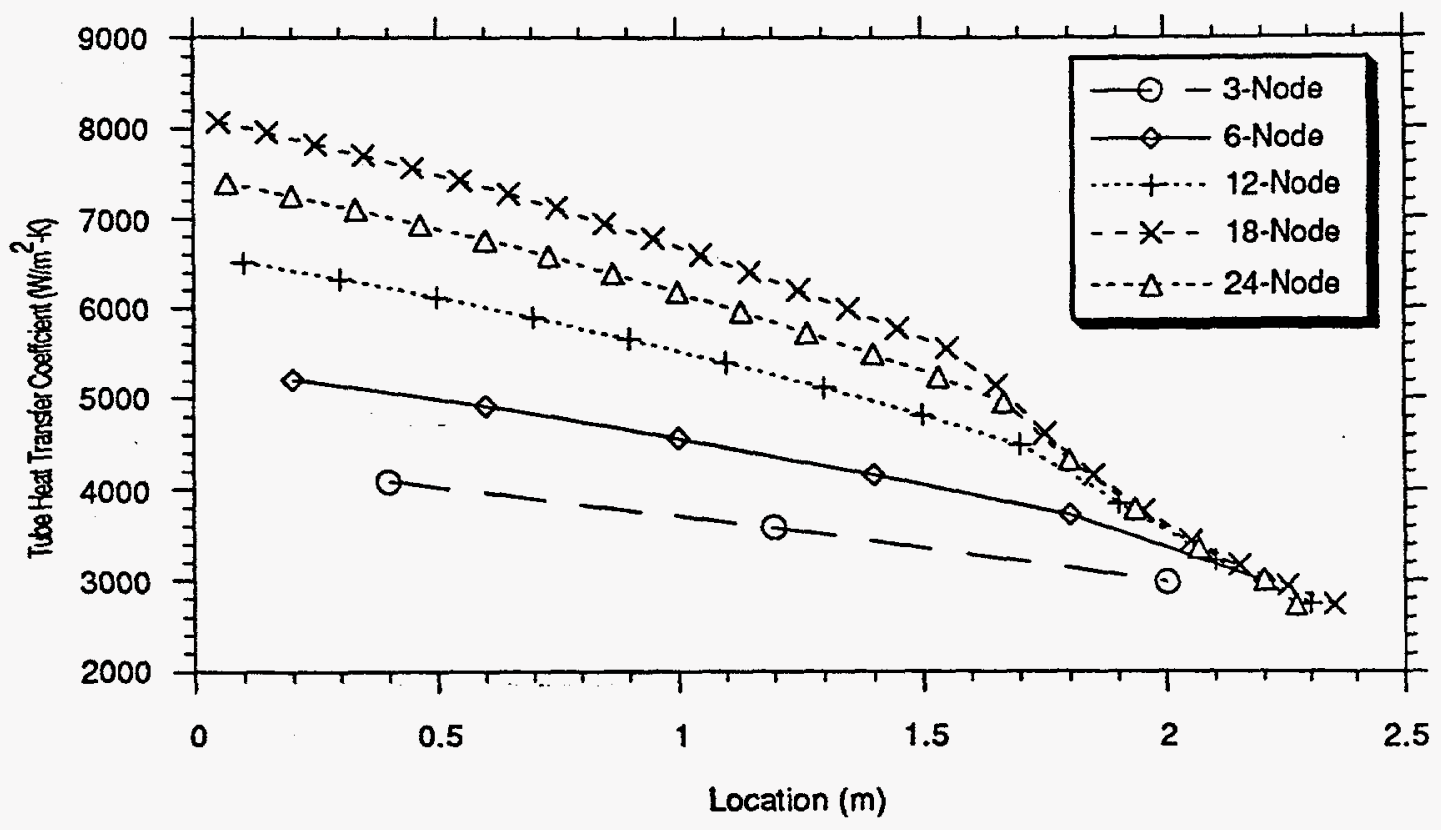

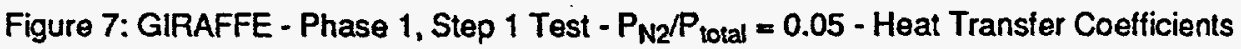

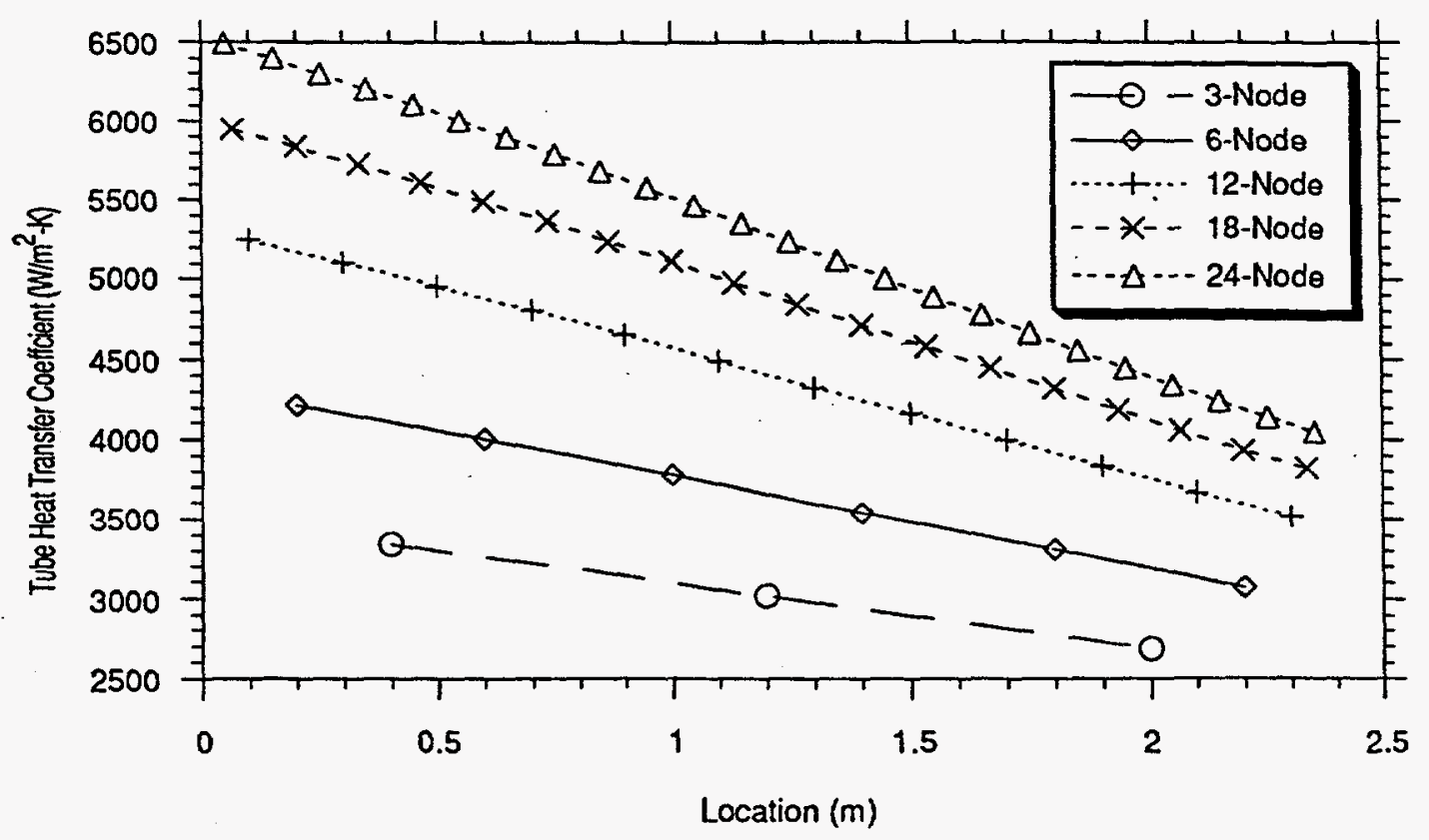

Figure 8: GIRAFFE - Phase 1, Step 1 Test $-P_{\mathrm{N} 2} / P_{\text {total }}=0.10-$ Heat Transfer Coefficients 


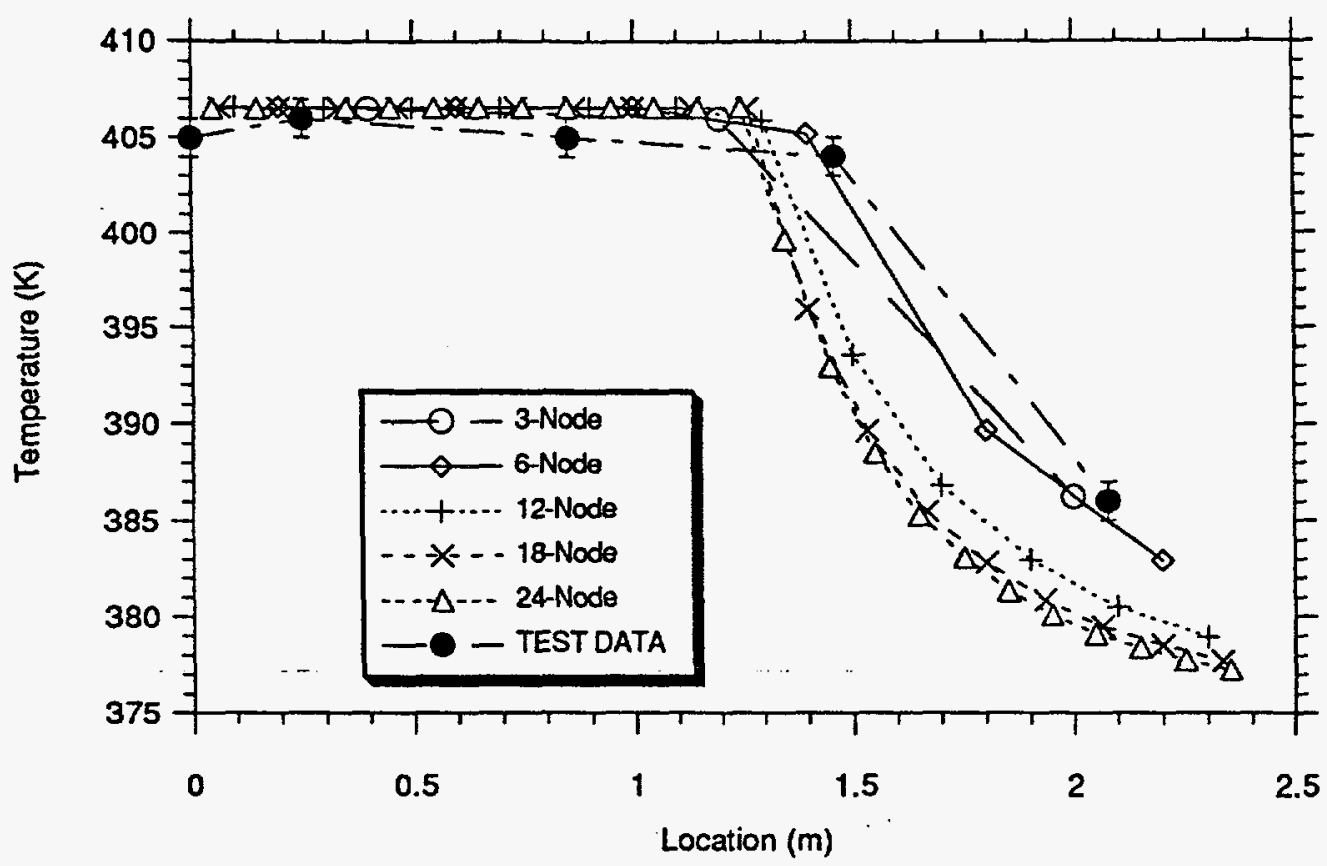

Figure 9: GIRAFFE - Phase 1, Step 1 Test- $P_{N 2} / P_{\text {total }}=0.0$ - Temperatures

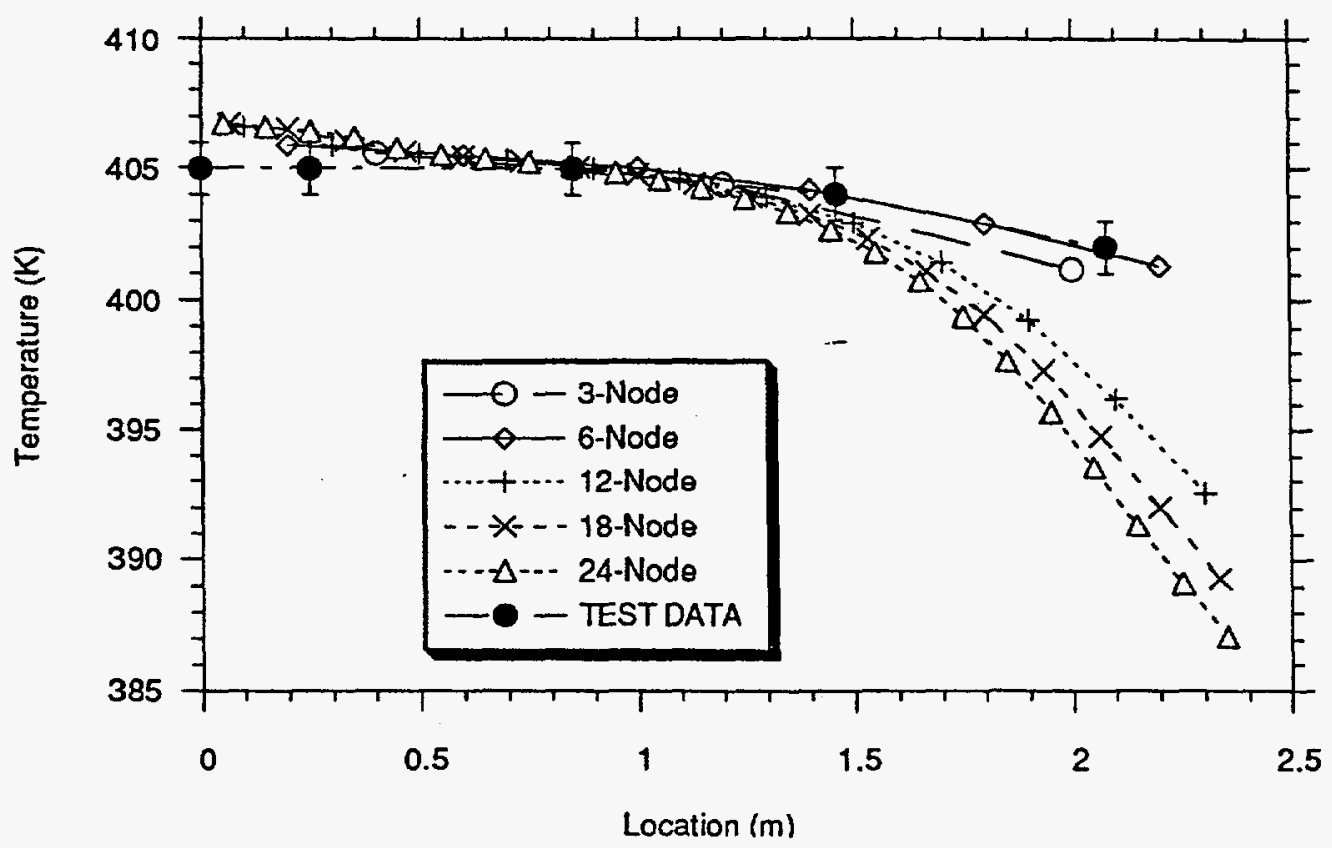

Figure 10: GIRAFFE - Phase 1, Step 1 Test $-P_{N 2} / P_{\text {total }}=0.02-$ Temperatures 


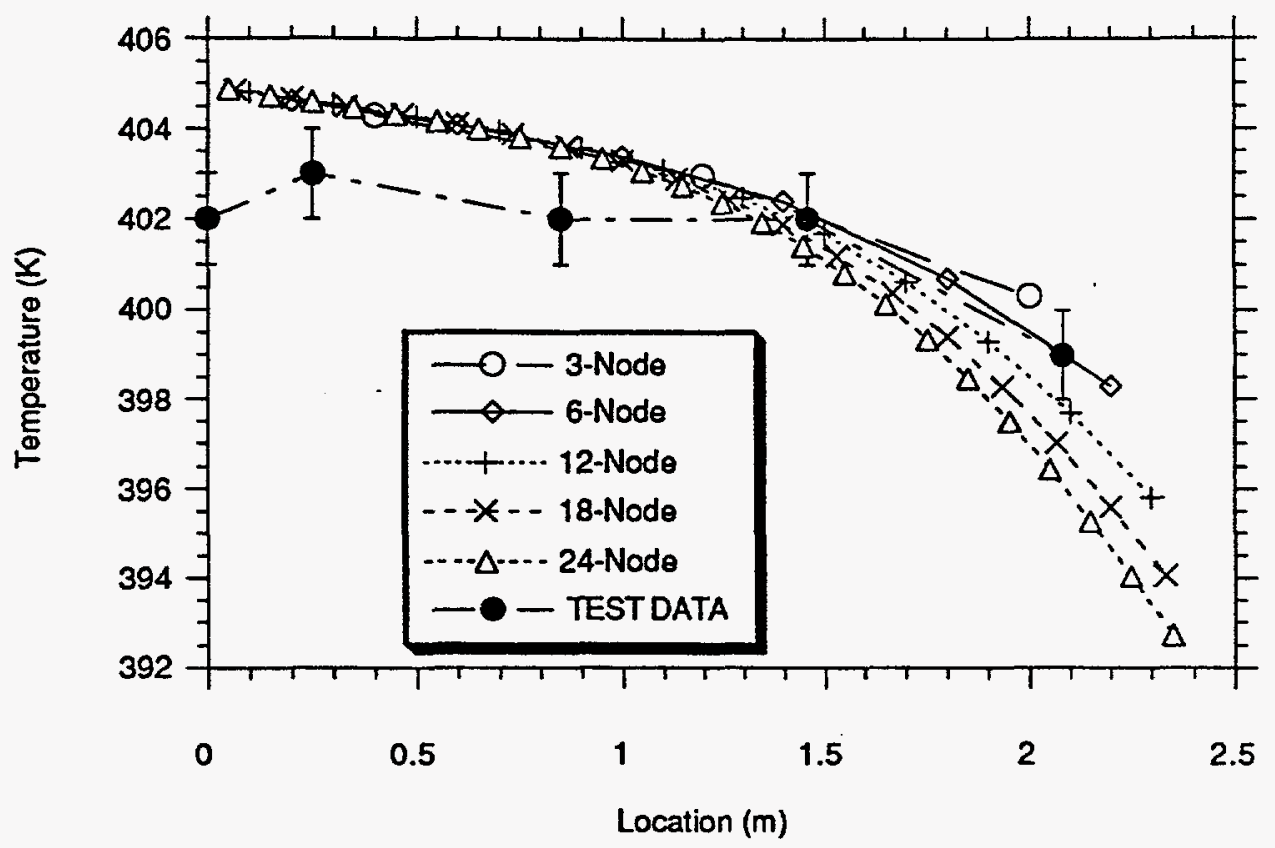

Figure 11: GIRAFFE - Phase 1, Step 1 Test $-P_{\mathrm{N} 2} / P_{\text {total }}=0.05-$ Temperatures

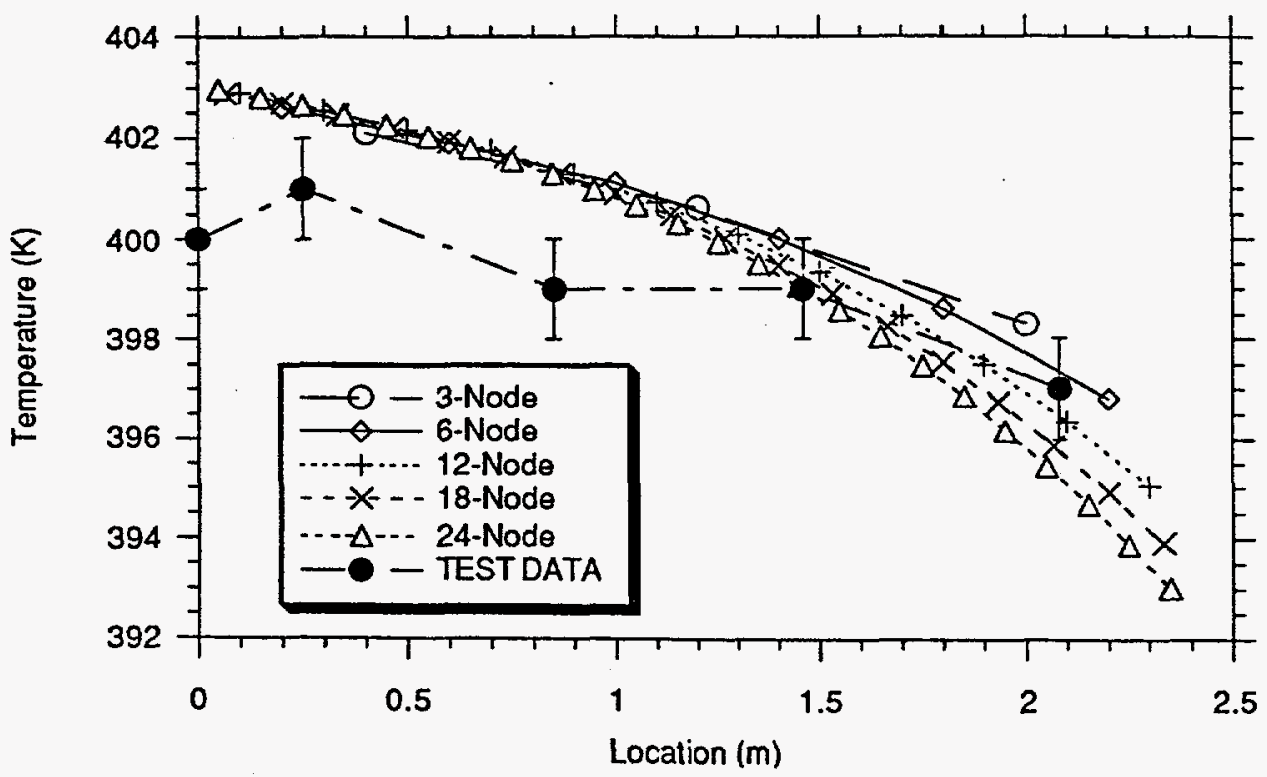

Figure 12: GIRAFFE - Phase 1, Step 1 Test $-P_{\mathrm{N} 2} / P_{\text {total }}=0.10-$ Temperatures 


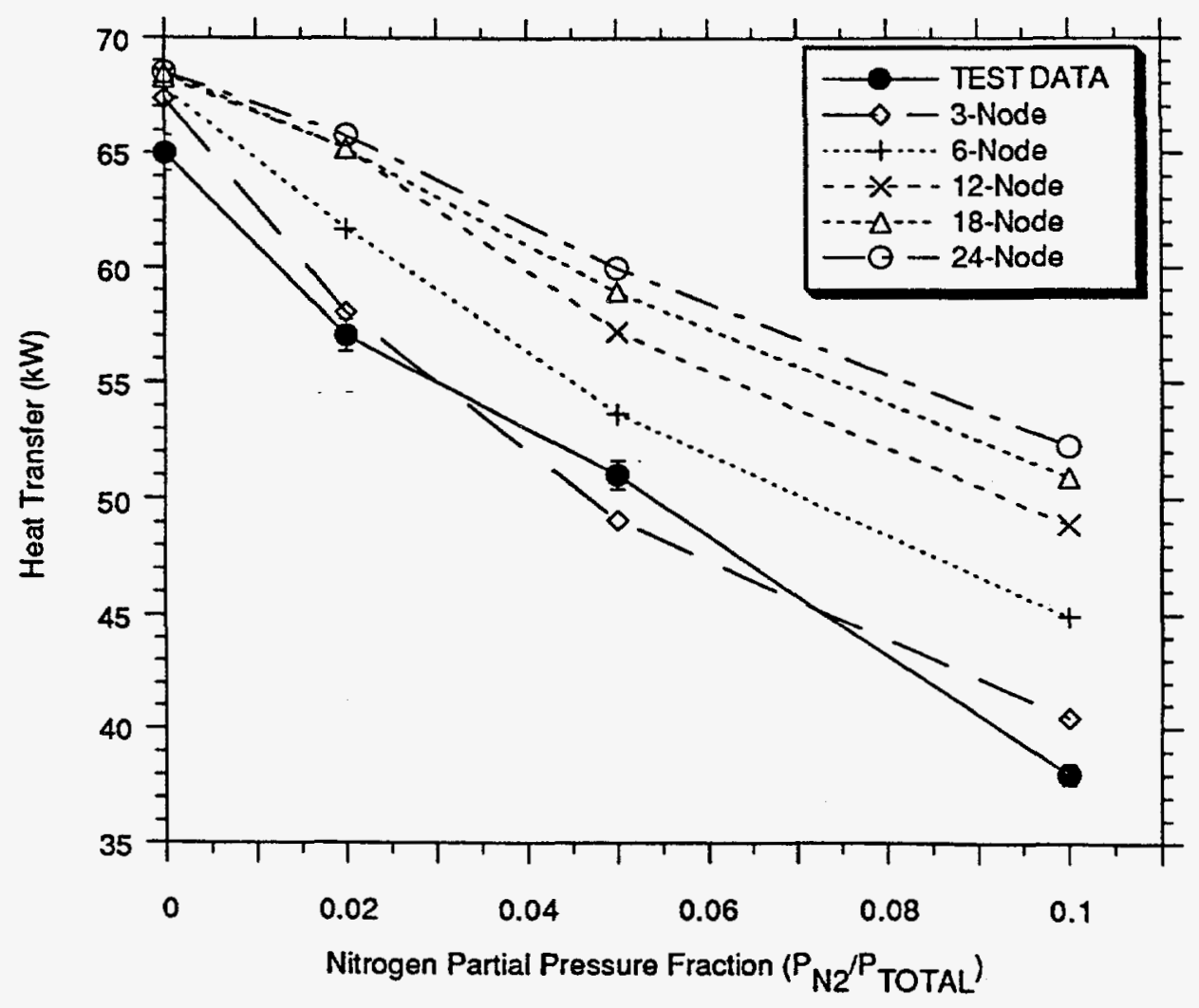

Figure 13: GIRAFFE - Phase 1, Step 1 Test - Heat Transfer Rates 
Table 1: RELAP5 Pool Boiling Curve

\begin{tabular}{|c|c|c|}
\hline $\begin{array}{l}\text { Temperature } \\
\text { (K) }\end{array}$ & & $\begin{array}{l}\text { Heat Transfer Coefficient } \\
\left(W / m^{2}-K\right)\end{array}$ \\
\hline 373.25 & & 169.0 \\
\hline 373.65 & & 290.0 \\
\hline 374.15 & & 365.0 \\
\hline 375.15 & & 460.0 \\
\hline 376.15 & & 526.0 \\
\hline 376.65 & & 554.0 \\
\hline 376.83 & & 1380.0 \\
\hline 377.59 & & 1480.0 \\
\hline 377.77 & & 1650.0 \\
\hline 378.13 & & 1810.0 \\
\hline 379.15 & & 2370.0 \\
\hline 380.15 & & 3250.0 \\
\hline 381.15 & & 4280.0 \\
\hline 382.15 & & 5460.0 \\
\hline 383.15 & & 6780.0 \\
\hline 384.15 & & 8250.0 \\
\hline 385.15 & & 9860.0 \\
\hline 386.15 & & 11600.0 \\
\hline 387.15 & & 13500.0 \\
\hline 388.15 & & 15600.0 \\
\hline 389.15 & & 17800.0 \\
\hline 390.15 & & 20200.0 \\
\hline 391.15 & & 22700.0 \\
\hline 392.15 & & 25400.0 \\
\hline 393.15 & & 28200.0 \\
\hline 394.15 & & 31200.0 \\
\hline 395.15 & & 34300.0 \\
\hline 396.15 & & 34300.0 \\
\hline 397.15 & & 34300.0 \\
\hline 398.15 & & 34300.0 \\
\hline 399.15 & & 34300.0 \\
\hline 401.15 & & 25900.0 \\
\hline 403.15 & & 18700.0 \\
\hline 407.15 & - & 10400.0 \\
\hline 411.15 & & 6160.0 \\
\hline 415.15 & & 3850.0 \\
\hline 419.15 & & 2510.0 \\
\hline 423.15 & & 1700.0 \\
\hline 427.15 & & 1180.0 \\
\hline 431.15 & & 845.0 \\
\hline 435.15 & - & 617.0 \\
\hline 439.15 & & 460.0 \\
\hline 443.15 & & 349.0 \\
\hline 445.15 & & 306.0 \\
\hline 453.15 & & 300.0 \\
\hline 463.15 & & 278.0 \\
\hline 473.15 & & 260.0 \\
\hline 483.15 & & 255.0 \\
\hline 493.15 & & 250.0 \\
\hline
\end{tabular}

